\title{
Medhelp: A Mobile Application to Connect Pilgrims with First-aiders during Al-hajj
}

\author{
Salma Elhag \\ Assistant Professor \\ King Abdulaziz \\ University, Saudi Arabia
}

\author{
Malak Alqarni \\ King Abdulaziz \\ University, Saudi Arabia
}

\author{
Juman Ahmad \\ King Abdulaziz \\ University, Saudi Arabia
}

\author{
Meznah Humidan \\ Alsalhi \\ King Abdulaziz \\ University, Saudi Arabia
}

\begin{abstract}
This project is one of the applications that support the first-aid services in Al-Hajj. The pilgrim can request medical services according to location. It also displays the profile of the firstaider to keep the pilgrim aware of who will provide the service. The application view first aid instructions. It also provide fast medical assistance for pilgrims. Also, the application sends annual statistics for Al-Hajj through the records of pilgrims and first-aider during Al-Hajj.
\end{abstract}

\section{Keywords}

Mobile Application, Pilgrims, Hajj, first-aider, Medical help, GPS, location based help

\section{INTRODUCTION}

Hajj is an annual Islamic pilgrimage to Makkah. Huge numbers of Pilgrims come from all over the world to perform pilgrimage in makkah[3]. The total number of pilgrims in 2018 is $(2.371 .675)$ pilgrims, of whom $(1,758.722)$ pilgrims from outside the Kingdom of Saudi Arabia, while the number of pilgrims inside (612.953) pilgrims [1]. Managing and serving this huge number of people needs a lot of Effort and accuracy, many organizations want to provide services and products that could help pilgrims during their stay at makkah[2]. One of the main services is medical services, since haij is the fifth pillars of Islam, Muslims wait for their entire life to have this chance and be able to perform pilgrimage. At that time most of them become too old and probably have medical situations. That insure the need of medical help every ware and every time. Also, the weather in makkah is so hot and since people are coming from all over the world they might get sick because of the change of the weather. That could affect their performance and Lead to dizziness and fainting so that will cause crowed and pressure. Also, taking in consider that many of families comes with their children so they will face different medical situations since they are too young.

Medical services must be available in all places to help pilgrims to complete their pilgrimage and avoid many harms. That would be easer to using network to connect between pilgrims and medical staff in one station which is our mobile application.

\section{RELATED WORK}

\subsection{Asefny}

This application is made by Saudi Red Crescent authority, it allows users in emergency situations to:

Make announcement for an emergency.Send urgent messages to either Saudi red crescent or family members

The system support deaf and dumb

Track the emergency announcement and view updates
Enter details of medical history

Show nearest medical centers, hospitals and pharmacies with GPS track

Home page is clear and simplified the main tasks with icons and small sentences, categories are clear and divided into menu bar.

It support Arabic, English, Urdu, French, Indonesia, and Filipino.

Users can make calls with all emergency centers in Saudi Arabia.

\subsection{CodeBlue}

This application allow people who needs medical help to request a near help provider using GPS until ambulance arrives.

Allow users to report for emergency situation and request help.

Patient can determine the medical situation and type details of the case

System shows medical help provider information

Home page is simple, the system detects location immediately, there is shortcuts for common emergency situations and (other) option, also space for typing details of the situation.

\subsection{DCAS Smart services}

This application consider as smart gate for Dubai ambulance services. Users can view information and apply for the organization

services.

Provide ambulance services for events and activities

Provide online payment method

Support English and Arabic

\subsection{Find Emergency Medical Help UK}

This application allow users to check nearest NHS emergency medical location (Accident \& emergency, urgent care centers, minor injuries units, walk in centers).

View locations of all emergency medical location in UK.

Provide contact numbers of each location .

View working hours of each location 


\section{METHODOLOGY}

The development of any information system framework that is used to structure, plan, and control it . This framework called Software Development Methodology (SDM) [4].

There are different type of methodologies and each type has advantage and weakness.

We have compared four methodologies to choose the best and most suitable from our project idea. The first methodology is Prototyping: It is a systems development method (SDM) in which a prototype is built, tested, and then reworked as necessary until an acceptable prototype is finally achieved [6].

The second methodology is Spiral: The spiral model combines the idea of iterative development with the systematic, controlled aspects of the waterfall model with very high emphasis on risk analysis [4].

The third methodology is Rational Unified Process (Rup): Is a software development process from Rational, a division of IBM. It divides the development process into four distinct phases that each involve business modeling, analysis and design, implementation, testing, and deployment. [7].

The fourth methodology is Waterfall : it is a sequential design process. The outcome of one phase acts as the input for the next phase sequentially, also referred to as a linearsequential life cycle model[4].

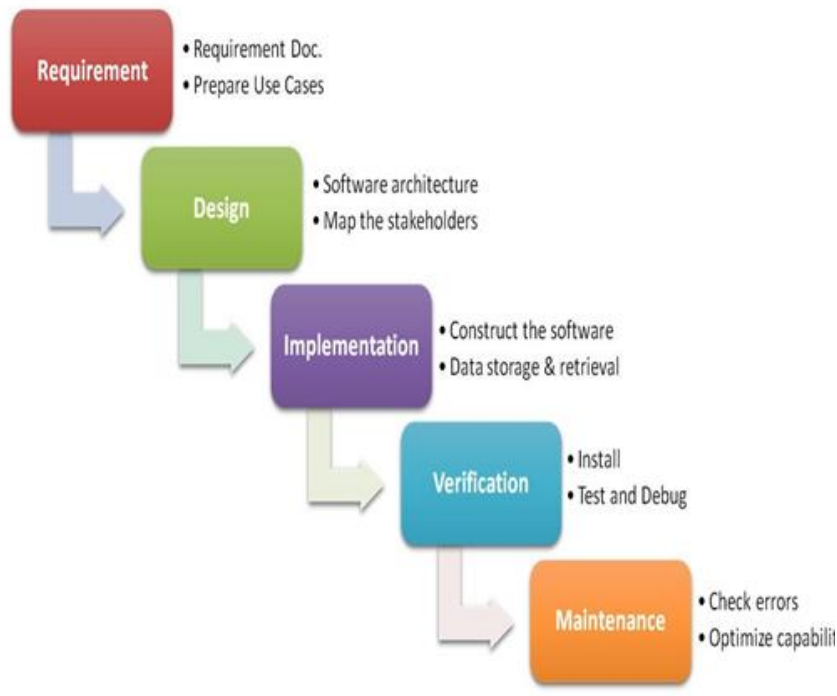

Figure 1.Water Fall Development Process

Waterfall development process (See Fig. 1) at the end of each phase, a review takes place to determine if the project is on the right path and whether or not to continue or discard the project. In this model software testing starts only after the development is complete. In waterfall model phases do not overlap [5].

And the best choice for development project idea is waterfall.

We chose waterfall to develop MedHelp for these reasons:

MedHelp has clear requirements.

MedHelp do not need to interaction with the customer for feedback .

MedHelp is medium project.
MedHelp definition is stable.

MedHelp focus on the quality more than cost [4].

\section{PROPSED SYSTEM}

We propose in this project is directed to pilgrims in the hajj season to help them to spend their hajj process easily and in a good health. The main aim of MedHelp is to providing medical help to pilgrims in the shortest time, reduce the damage

\section{RESULTS}

\subsection{Database Design}

The Database of MedHelp consists of four tables which are Admin Table, First Aider Table, pilgrim Table and Request Table.

\subsection{Graphical User Interface Design}

The following are some pages for the GUI:

Admin pages:

1- Login page of admin: ID, password it's required for entering.

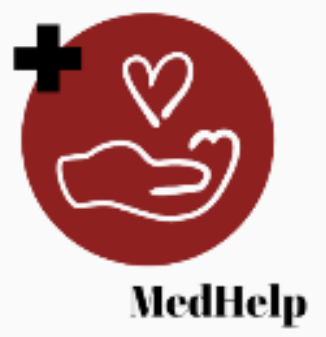

ID

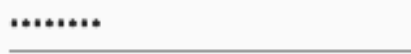

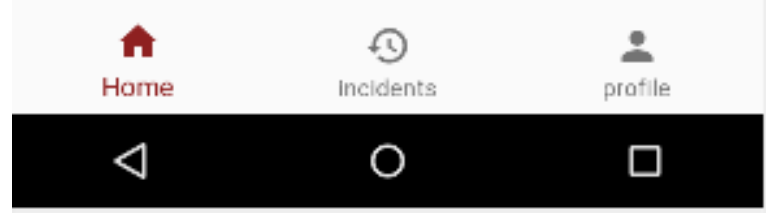

Figure 2.Llogin page of admin

1. Incidents page: it displays a summary of the incidents for each day.

2. Incidents of a specific day for example "2 December "Will show the location, status, date of the incidents. 


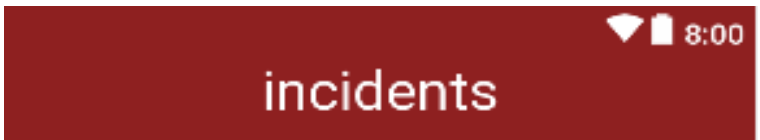

2 DECEMBER

3 DECEMBER

4 DECEMBER

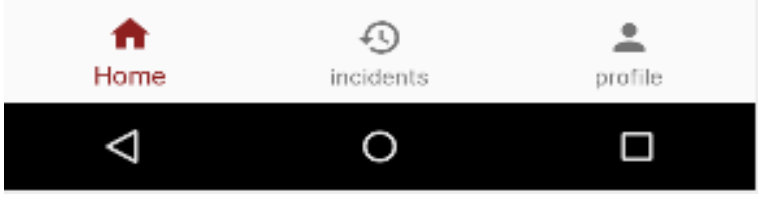

Figure 3.Incidents page of admin
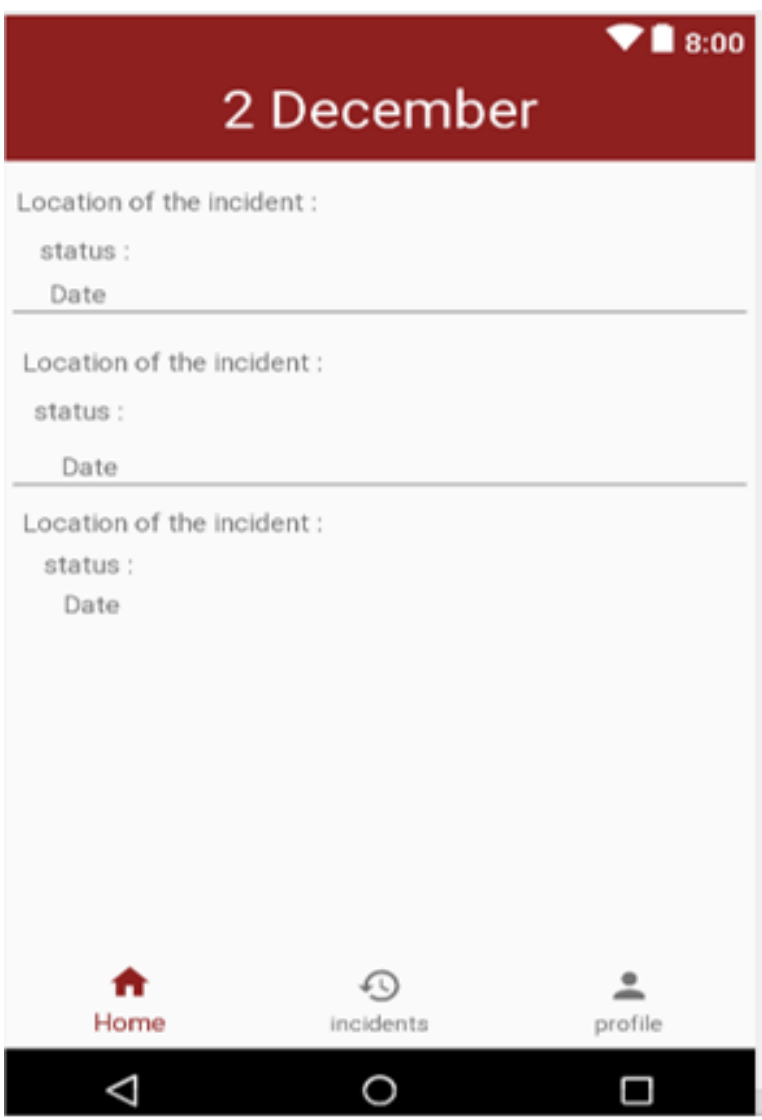

Figure 4.Incidents page of 2 December
Pilgrim pages:

1. -FirstPage: when the user opens the application, this interface will show

2. Register page: the pilgrim should register and fill all required fields to enable request serve of help.

3. Login page: ID, password it's required for entering.

4. HomePage: This interface allows to the pilgrim to request a first-aider with few steps like the choose status and other details

\section{MedHelp}

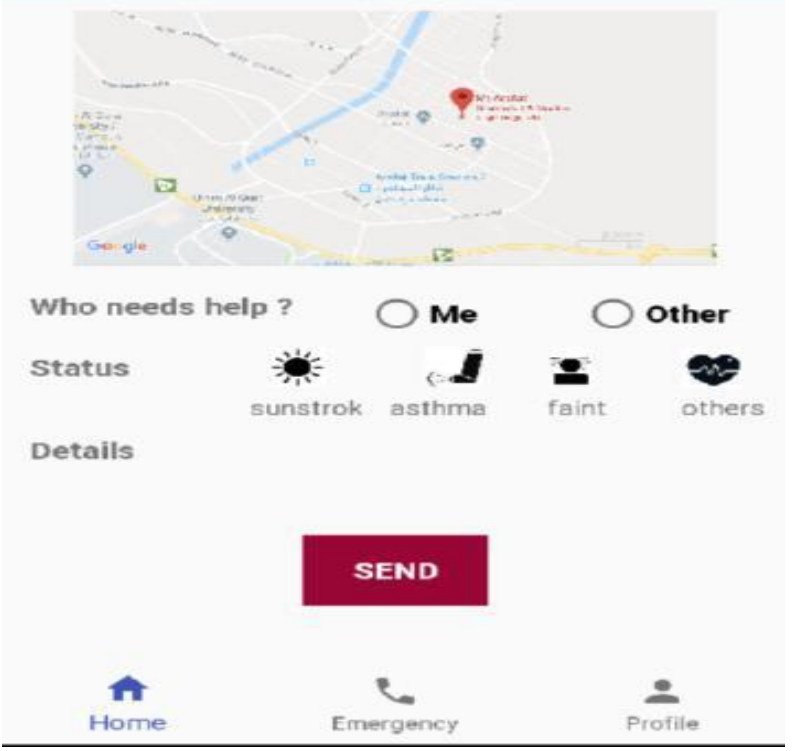

Figure 5. Home page of pilgrim

4-Emergency page: This interface allows to the pilgrim to call inside the application just click on call button

5-Profile page: In this interface the pilgrim can complete his/her information

\section{MedHelp}

Unified Emergency Number
Red Crecent
Police
Civil Defence
Ministry Of Health
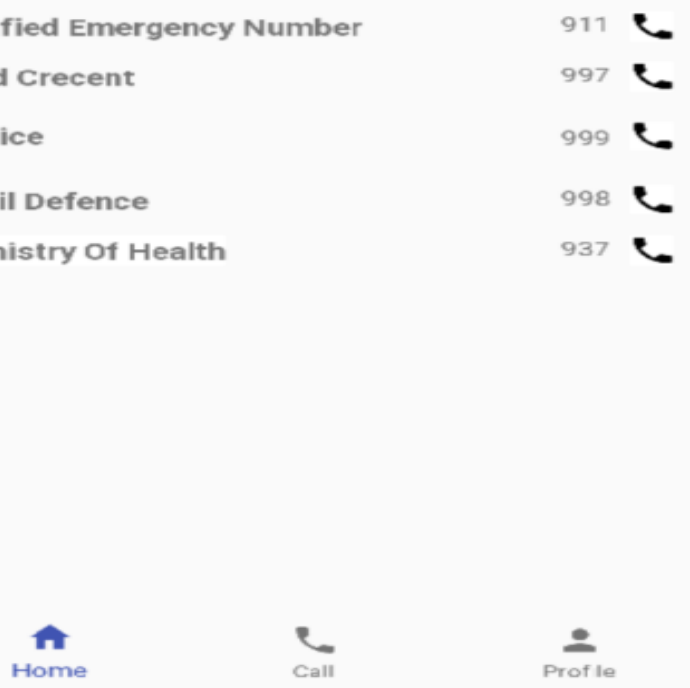

Figure 6.Emergency page 
5-Incidents page: In this interface the pilgrim can see history from his/her request

\section{MedHelp}

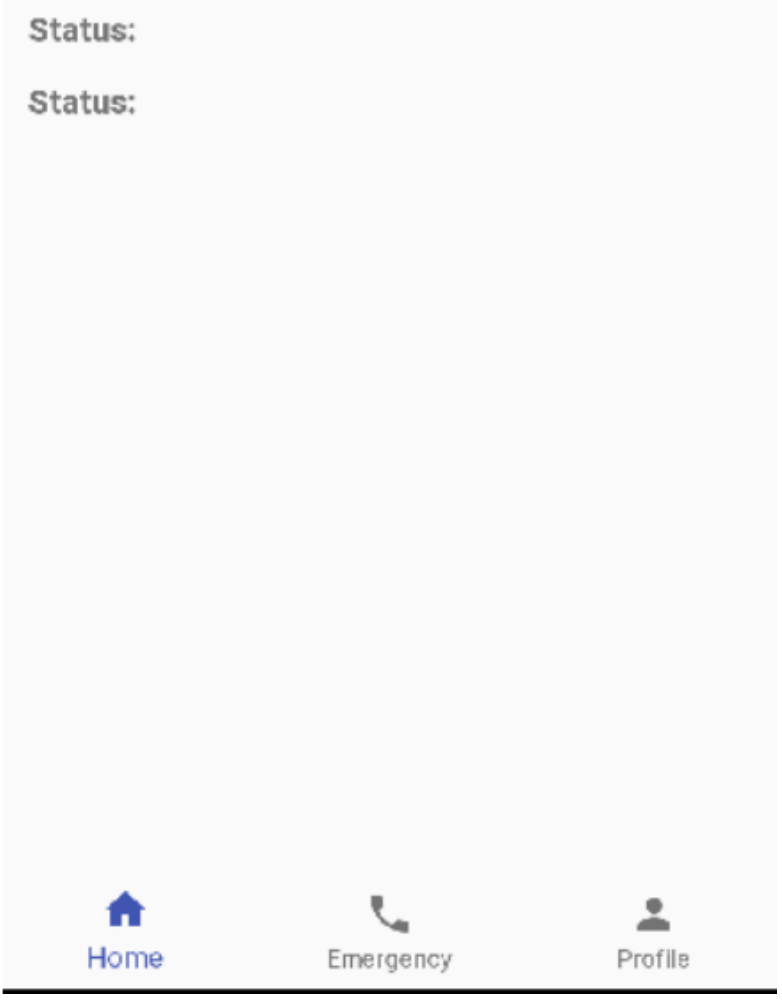

Figure 7.Incidents page of pilgrim

First-aider pages:

1- Login page: each first aider has an ID to log in with

2- -Home page: in this page a first-aider receives the requests from pilgrims that will be shown with status type and the name of the pilgrim, it also provides tracking to the pilgrim's location after accepting the request

\section{MedHelp}

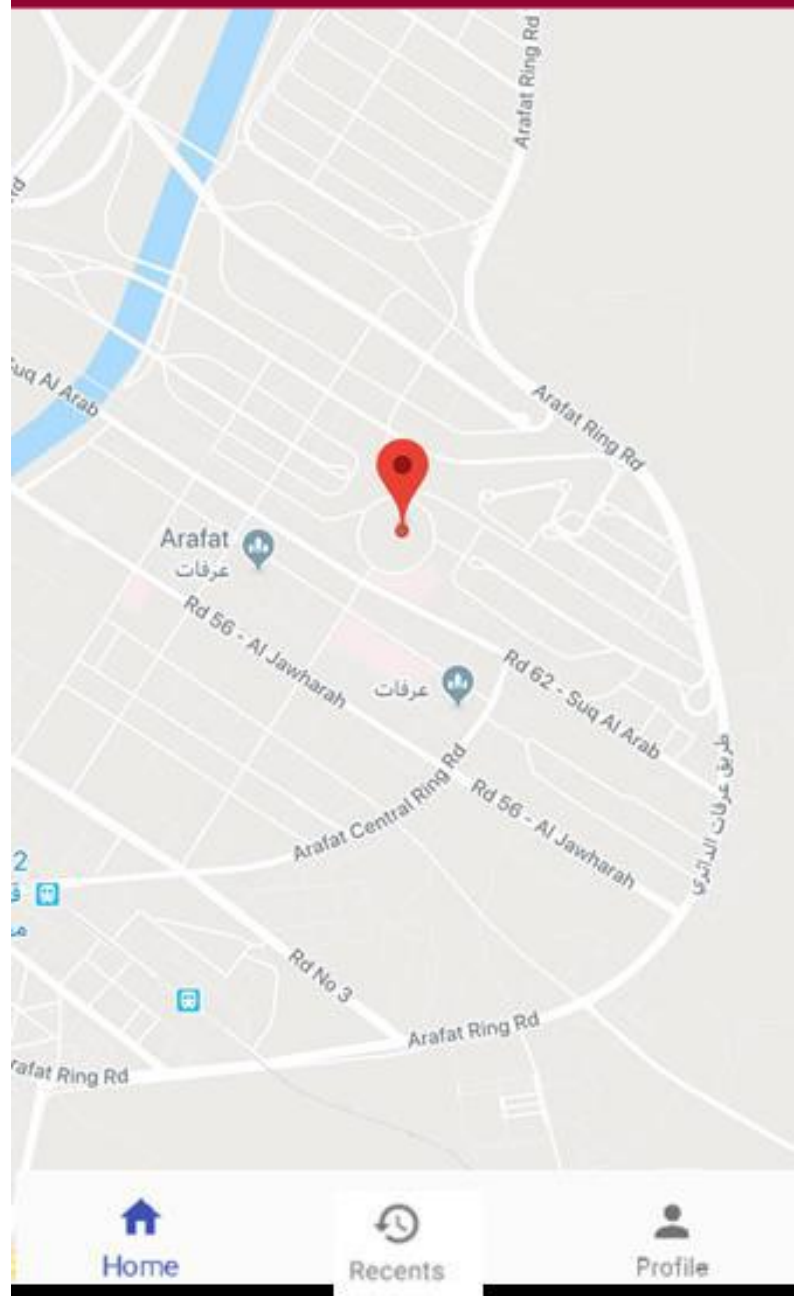

Figure 8. Home page of first-aider

3- Recent page: this page represents the recent requests that processed by the first-aider according to time and date

4- Profile page: this page represents the personal information of the first aider 


\section{MedHelp}

\begin{tabular}{lc} 
Status: Faint & $18 \mathrm{nov}$ \\
\hline Status: Sunstrock & $18 \mathrm{nov}$ \\
\hline Status: Others & $19 \mathrm{nmv}$ \\
\hline
\end{tabular}
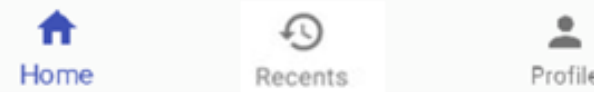

Figure9.Recent page of first-aider

\section{DISCUSSION}

The results of this study address two aspects; analysis and design of a smart mobile application to help providing medical first aids to pilgrims. Critiqued Comparisons of Similar existing applications was provided such as ; Asefny, ,CodeBlue, DCAS Smart services and Find Emergency Medical Help UK.

After concluding survey and interviews; the results concluded to requirements of the system that have been carried to design and implementation.

\section{ACKNOWLEDGMENTS}

Our thanks to all who have contributed towards development of our work.

\section{REFERENCES}

[1] General Authority for Statistic (2017),"General summary of Al-Hajj statistics" , Available at : https://www.stats.gov.sa/sites/default/files/haj_1438.pdf (accessed 10 September 2018).

[2] Voluntary health programmer (2010) ,"Al-Hajj health volunteer program ", Available at http://volunteers.hajjhealth.org/ (accessed 10 September 2018)
[3] Ministry of Haj and Umra.[online] Available at: http://www.haj.gov.sa/english/Pages/default.aspx [Accessed 10 Sep. 2018].

[4] Sommerville, I. (2015). Software Engineering. 10th ed. Old Tappan: Pearson Education UK.

[5] Cittasolutions.com Model[online]Available

Waterfall https://cittasolutions.com/waterfall-model [Accessed 8 Oct. 2018].

[6] Rouse, M. (2005). What is Prototyping Model? Definition from WhatIs.com.[online]SearchCIO.Availableat:https://searc hcio.techtarget.com/definition/Prototyping-Model [Accessed 12 Oct. 2018].

[7] Techterms.com. (2018). RUP (Rational Unified Process) Definition. [online] Available at https://techterms.com/definition/rup [Accessed 12 Oct 2018].

[8] Srca Org, "Asefny”, Apple App Store.

[9] Code Blue Sa "CodeBlue", Apple App Store.

[10] Appadvice, "DCAS Smart Services", Apple App Store.

[11] Arabyapps, "Find Emergency Medical Help UK", Apple App Store.

[12] Users.csc.calpoly.edu. (2018). Nonfunctional Requirements.[online] Available at: http://users.csc.calpoly.edu/ jdalbey/SWE/QA/nonfuncti onal.html [Accessed 19 Nov. 2018].

[13] www.tutorialspoint.com(2018). Functional Requirements [online] Available at https://www.tutorialspoint.com/software_testing_diction ary/functional_requirements.htm[Accessed 23 Nov. 2018].

[14] Vectors, R., Vectors, H. and Image, C. (2018). Cartoon girls with hijab vector image on VectorStock. [online] VectorStock. Available

at: https://www.vectorstock.com/royalty-freevector/cartoon-girls-with-hijab-vector-8821370 [Accessed 23 Nov. 2018].

[15] www.tutorialspoint.com. (2018). Functional Requirements.[online] Available at: https://www.tutorialspoint.com/software_testing_diction ary/functional_requirements.htm [Accessed 23 Nov. 2018].

[16] Android Developers. (2019). Download Android Studio and SDK tools | Android Developers. [online] Available at: https://developer.android.com/studio/ [Accessed 28 Jan. 2019].

[17] Homepages.inf.ed.ac.uk. (2019). [online] Available at: http://homepages.inf.ed.ac.uk/da/teach/HCI/rules.pdf [Accessed 28 Jan. 2019].The Interaction Design Foundation. (2019). User Interface Design Guidelines:

[18] 10 Rules of Thumb. [online] Available at: https://www.interaction-design.org/literature/article/userinterface-design-guidelines-10-rules-of-thumb [Accessed 28 Jan. 2019]. 